\title{
Maintien du potentiel adaptatif chez les plantes domestiquées à propagation clonale
}

Leçons de gestion par les cultivateurs de manioc amérindiens

Doyle McKey, Marianne Elias, Benoît Pujol, Anne Duputié, Marc Delêtre et Delphine Renard

\section{CpenEdition}

\section{Journals}

Édition électronique

URL : http://journals.openedition.org/ethnoecologie/741

DOI : $10.4000 /$ ethnoecologie.74

ISSN : 2267-2419

\section{Éditeur}

Laboratoire Eco-anthropologie et Ethnobiologie

\section{Référence électronique}

Doyle McKey, Marianne Elias, Benoît Pujol, Anne Duputié, Marc Delêtre et Delphine Renard, « Maintien du potentiel adaptatif chez les plantes domestiquées à propagation clonale », Revue d'ethnoécologie [En ligne], 1 | 2012, mis en ligne le 29 novembre 2012, consulté le 30 avril 2019. URL : http:// journals.openedition.org/ethnoecologie/741 ; DOI : 10.4000/ethnoecologie.741

Ce document a été généré automatiquement le 30 avril 2019

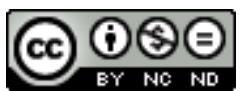

Revue d'ethnoécologie est mis à disposition selon les termes de la licence Creative Commons Attribution - Pas d'Utilisation Commerciale - Pas de Modification 4.0 International. 


\section{Maintien du potentiel adaptatif chez les plantes domestiquées à propagation clonale}

Leçons de gestion par les cultivateurs de manioc amérindiens

Doyle McKey, Marianne Elias, Benoît Pujol, Anne Duputié, Marc Delêtre et Delphine Renard

\section{Introduction}

1 Le manioc (Manihot esculenta Crantz, Euphorbiacées), plante originaire de l'Amazonie, est aujourd'hui cultivé dans l'ensemble des régions tropicales. Cultivé pour ses racines charnues riches en amidon, le manioc constitue la base de l'alimentation de près d'un milliard de personnes (IFAD/FAO 2008), un nombre qui augmente chaque jour. Dans le monde de demain, où les changements climatiques conduiront à des sécheresses plus fréquentes et où les pressions démographiques croissantes amèneront les paysans à cultiver des sols de moins en moins fertiles, ses avantages agronomiques particuliers feront du manioc une plante encore plus importante. Mais si le manioc est l'une des plantes alimentaires les moins exigeantes et peut aller jusqu'à tolérer des conditions écologiques parfois marginales pour l'agriculture, c'est de sa gestion par les agriculteurs que dépend la durabilité de sa culture. Cette gestion se doit de prendre en compte les spécificités du manioc, qui sont liées d'une part à ses adaptations particulières, et d'autre part aux contraintes évolutives que le manioc partage avec d'autres plantes propagées par les cultivateurs par bouturage (McKey et al. 2010b, 2011). Depuis qu'ils l'ont domestiqué, il y a près de 7000 ans (Piperno et al. 2000, Dickau et al. 2007), les Amérindiens d'Amazonie pratiquent une gestion habile du manioc, mais souvent mal comprise par les scientifiques. Leurs pratiques traditionnelles offrent des leçons précieuses pour la culture durable non seulement du manioc, mais également d'autres plantes à propagation clonale (Rival \& McKey 2008). Sous une forme narrative, cet essai offre un résumé de nos études 
de la gestion du manioc par ses cultivateurs ${ }^{1}$ amérindiens, et de ce qu'elles impliquent pour la culture durable du manioc dans toute la ceinture intertropicale.

\section{Le doux et l'amer}

2 Dans les sociétés à manioc du bassin amazonien - et ailleurs dans les basses-terres sudaméricaines, comme dans les Guyanes ${ }^{2}$ où nous avons conduit nos études - le manioc est consommé matin, midi et soir. Mais ce n'est pas un inconvénient à la longue, parce qu'il existe une grande diversité de préparations culinaires, et une grande diversité variétale : des maniocs avec des cycles de culture plus ou moins longs, des tubercules plus ou moins jaunes ou blancs, avec des textures particulières, et des maniocs « doux » ou " amers ». Chez ces derniers, la préparation assure une fonction assez inhabituelle : il faut d'abord éliminer un poison mortel. Ce problème ne se pose pas pour les variétés de manioc dites "douces", dont les racines peuvent être consommées sans préparation particulière, bouillies, grillées ou frites. Mais les variétés « amères ", nettement majoritaires partout en Amazonie (sauf dans une région restreinte d'Amazonie occidentale, au Pérou et en Équateur), demandent une préparation très particulière. Le manioc amer est la seule plante alimentaire majeure qui soit mortellement toxique si elle n'est pas préparée correctement. Le manioc est une plante cyanogénique (c'est-à-dire, produisant des composés qui libèrent du cyanure). Chez les variétés douces, la teneur des racines en composés cyanogéniques est très faible. Par contre, chez les variétés amères, dans les racines comme dans le reste de la plante, ces composés sont présents en concentrations élevées. Il s'agit de deux glucosides cyanogéniques, la linamarine (très majoritaire) et la lotaustraline (McMahon et al. 2005). Ces glucosides en eux-mêmes ne sont pas toxiques, mais lorsqu'ils sont hydrolysés par une enzyme, la glucosidase, également présente dans la plante, mais dans un autre compartiment cellulaire, de l'acide cyanhydrique (HCN) est libéré. Ceci ne se produit que lorsque l'enzyme et son substrat se rencontrent, lorsque la structure de la cellule est rompue, par exemple suite à l'attaque d'un herbivore - tel l'homme - ou d'un organisme pathogène.

\section{... le manioc amer produit de l'acide cyanhydrique, qu'il faut éliminer par une préparation laborieuse}

3 Les racines du manioc amer renferment de fortes concentrations en glucosides cyanogéniques et doivent donc être détoxifiées. La simple cuisson ne suffit pas à la détoxification, car si les glucosidases sont dénaturées, les glucosides, eux, restent intacts (McKey \& Beckerman 1993; McKey et al. 2010a). Que se passe-t-il si on mange du manioc amer qui a été simplement bouilli ? L'issue semble dépendre de la flore intestinale du sujet, qui produit, selon les personnes, plus ou moins de glucosidases capables de libérer l'acide cyanhydrique. La seule manière fiable de détoxifier le manioc amer est donc d'abord d'hydrolyser les glucosides, et ensuite d'éliminer l'acide cyanhydrique, qui est soluble dans l'eau et peut être alors volatilisé par la chaleur. L'hydrolyse des glucosides peut être effectuée en suivant différents procédés : le râpage mécanique des racines, ou bien le rouissage, c'est-à-dire la fermentation lors du trempage des racines plusieurs jours dans l'eau. Une procédure répandue en Amazonie consiste à râper les racines de manioc à 
l'aide d'une planche en bois garnie de milliers de petites pointes en métal (autrefois, c'étaient de petits morceaux de quartzite encastrés dans le bois) (Photo 1).

Photo 1. Râpage des racines de manioc amer dans un village Makushi

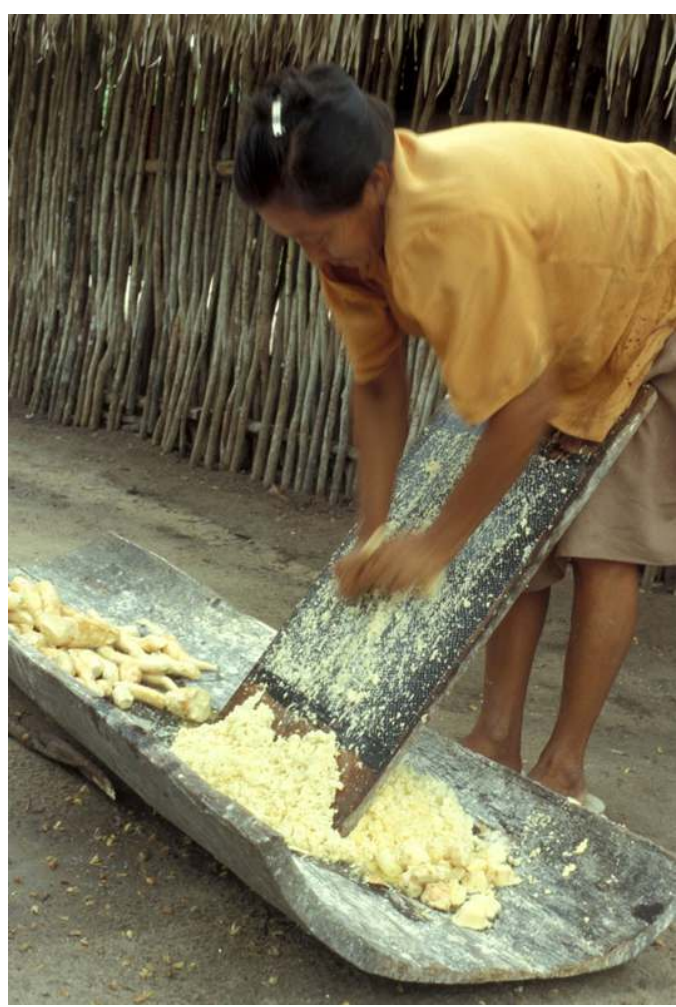

(Photo Doyle McKey)

4 Le râpage détruit les cellules, permettant l'hydrolyse des glucosides et la libération de l'acide cyanhydrique. Comment éliminer l'acide cyanhydrique libéré ? Un moyen répandu en Amazonie est d'utiliser la "couleuvre à manioc", un tube en vannerie qui peut être comprimé ou étiré ; on y met la pulpe, on attache l'anneau qui se trouve à l'extrémité supérieure de la couleuvre au plafond de la hutte, on insère un levier dans l'anneau à l'autre bout, et l'on s'assoit sur le levier pour presser le jus, qui s'écoule dans un récipient (Photo 2). 
Photo 2. Utilisation de la « couleuvre à manioc » chez les Makushi
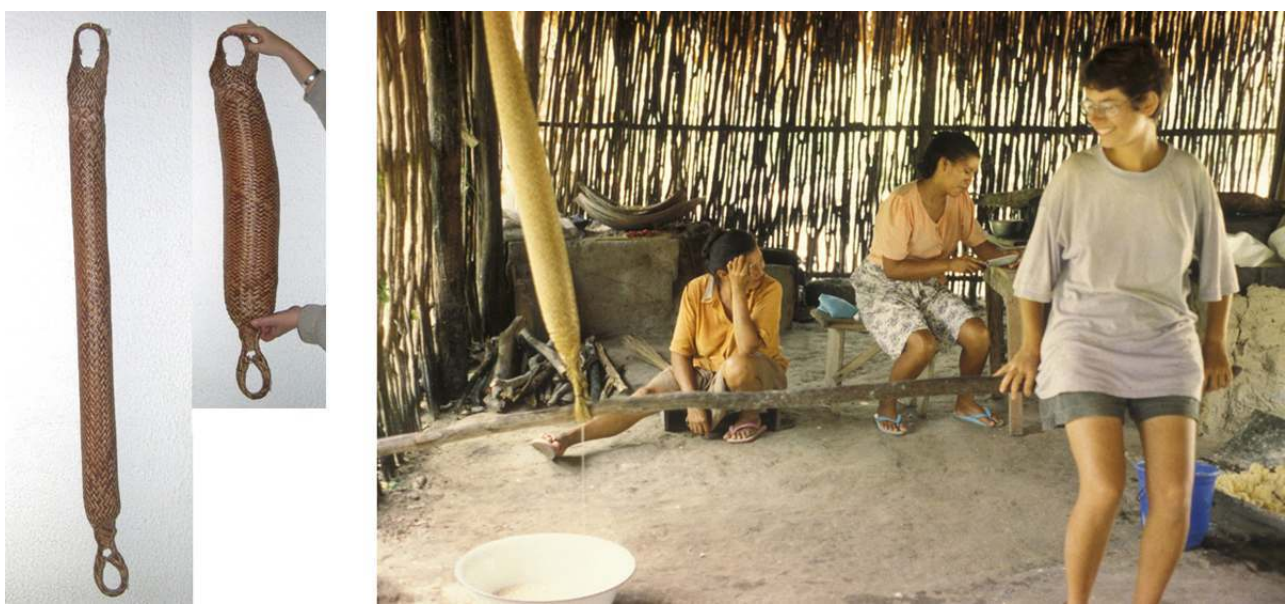

Marianne Elias montre comment le jus toxique est pressé de la pulpe râpée.

(Photo Doyle McKey)

Ce jus est toxique à l'état cru, mais l'acide cyanhydrique est éliminé par chauffage. Bouilli jusqu'à la caramélisation, ce jus est utilisé pour confectionner le kumasi ${ }^{3}$, un condiment servi avec le poisson ou la viande. Le filtrage du jus donne un amidon très fin, le tapioca, agréable au petit-déjeuner. Si les racines ont été râpées assez finement, un seul passage de la pulpe de manioc dans la couleuvre suffit à la détoxifier. Par la suite, la pulpe peut être façonnée en galettes de manioc (cassave $e^{4}$ ), qui peuvent être stockées durant de longues périodes. Ces galettes, trempées dans de l'eau, servent aussi comme matériel de base pour la fabrication de la bière de manioc, le parakîrî $\hat{\imath}^{5}$.

Pour faire la bière, il faut d'abord convertir l'amidon des racines en sucre, mais les racines de manioc ne renferment pas d'amylase, l'enzyme capable d'effectuer cette transformation. Les Amérindiens Makushi, ainsi que quelques autres ethnies de la même région du plateau des Guyanes, utilisent une procédure inédite (pour une description des procédures, sensiblement différentes, de l'élaboration de la bière du manioc dans une autre société amérindienne, les Wayãpi de la Guyane française, voir Grenand [1996]). Chez les Makushi, on prend de grosses galettes, on les trempe dans l'eau, on les dépose sur des feuilles de bananier sur le sol. Une poudre séchée de feuilles de manioc qui ont été attaquées par une moisissure (Henkel 2005) est saupoudrée sur les morceaux de galettes, puis ceux-ci sont trempés dans l'eau et disposés sur des feuilles de bananier placées par terre. C'est cette moisissure qui est source d'amylase. Quelques feuilles fraîches de manioc sont ajoutées, puis l'ensemble est recouvert de feuilles de bananier et laissé à fermenter. Deux jours plus tard, la moisissure a infecté les nouvelles feuilles, qui seront séchées, conservées, et utilisées pour la préparation du prochain lot de bière. La pulpe, attaquée par la moisissure, devient aussi sucrée que du miel! Mise de côté dans un pot en caoutchouc local, ou, plus récemment, dans un seau en plastique fermé, la pulpe, colonisée par des levures et fermentée, donne la bière de manioc, qui joue - ou a joué autrefois - un rôle social important dans toutes les sociétés cultivant du manioc.

7 Les Amérindiens préparent également la farine de manioc $\left(u^{\prime} w i^{6}\right)$. Dans ce cas, les racines sont mises à fermenter pendant quelques jours dans un marigot, où elles sont détoxifiées par l'activité des microorganismes. Les racines fermentées macèrent ensuite dans un bac et sont broyées. La pulpe, chauffée sur des grandes platines, donne après cuisson la farine 
de manioc. Tout comme les galettes, la farine peut être stockée durant des semaines, voire des mois.

\section{Pourquoi cultiver une racine mortellement toxique?}

8 La détoxification du manioc amer demande une préparation très laborieuse. Pourquoi les Amérindiens cultivent-ils cette plante si contraignante, alors qu'ils cultivent aussi le manioc doux?

9 Une partie de la réponse à cette question est que les glucosides cyanogéniques servent aussi de défense chimique contre les herbivores et les pathogènes dans les champs (McKey et Beckerman 1993 ; McKey et al. 2010a). Protégées par leur toxicité, les racines peuvent compléter leur développement et peuvent aussi être laissées longtemps dans le sol sans pourrir. Ce «stockage sur pied », permettant une récolte étalée dans le temps, est l'un des atouts agronomiques du manioc amer. Le manioc doux, quant à lui, est souvent planté près des maisons, où la présence humaine décourage certains ravageurs - pécaris et autres vertébrés -, et où les sols plus riches des jardins de case permettent une récolte souvent plus précoce.

\section{Une plante peu exigeante, dont la culture est vouée à s'étendre}

10 La toxicité du manioc amer contribue à un autre atout agronomique de cette plante. Ses adaptations permettant de conserver les ressources acquises par la photosynthèse et de les protéger de l'attaque des ravageurs confèrent au manioc la capacité de fournir des rendements intéressants dans des conditions écologiques que d'autres plantes ne tolèrent pas, tels que des sols pauvres ou des sécheresses. C'est cette rusticité qui fera du manioc une plante encore plus incontournable pour la sécurité alimentaire, dans un avenir marqué par le changement climatique et d'autres changements planétaires (IFAD/FAO 2005 ; Nhassico et al. 2005). Les pressions démographiques montantes (Collomb 1999) et la dégradation continue des écosystèmes tropicaux vont rendre une proportion croissante de sols exploitables uniquement pour la culture de plantes peu exigeantes, comme le manioc. Cependant, planté très abondamment et cultivé de plus en plus intensivement, le manioc va être confronté à de nouveaux défis.

\section{Des défenses imparfaites : la diversité génétique est garante du potentiel adaptatif}

11 Les maladies virales systémiques, telles que la mosaïque du manioc en Afrique, sont la première menace qui pèse sur cette plante. Et contre ces maladies, les défenses chimiques du manioc ont peu d'effet, pour deux raisons. Premièrement, les virus n'ont pas de métabolisme et ne sont donc pas affectés par un poison métabolique tel que l'acide cyanhydrique. Deuxièmement, les vecteurs de ces maladies sont des insectes piqueurssuceurs. Ils consomment la sève élaborée de la plante, à laquelle ils accèdent sans percer avec leur trompe les cellules où sont localisés les glucosides cyanogéniques et les 
glucosidases associées. Ces insectes sont donc également peu affectés par ces défenses chimiques.

En Afrique notamment, certains pathogènes, comme les nouvelles souches du virus de la mosaïque du manioc, sont particulièrement inquiétants (Fregene et al. 2004). Etant donnée l'inefficacité des défenses chimiques du manioc contre ces nouveaux défis viraux, il est essentiel de veiller au maintien de la diversité génétique de la plante, qui - comme pour tout organisme - est garante de son potentiel adaptatif.

\section{Comment maintenir la diversité génétique chez une plante à propagation clonale?}

13 Doit-on s'inquiéter de l'état de la diversité génétique du manioc? Oui, peut-être. Le manioc est propagé par voie clonale. Dans ce mode de propagation, qui caractérise bon nombre de cultures de la région tropicale humide telles que le bananier, le taro, les ignames et la patate douce, chaque plante de la nouvelle génération est une copie génétique identique - aux mutations somatiques près - d'une plante déjà présente dans la génération précédente. Le manioc est propagé par boutures de tiges (Photo 3); d'autres organes peuvent être utilisés pour le bouturage chez d'autres plantes : cormes (bananiers et taro) ou tubercules (ignames).

Photo 3. Propagation du manioc par des boutures de tige chez les Makushi

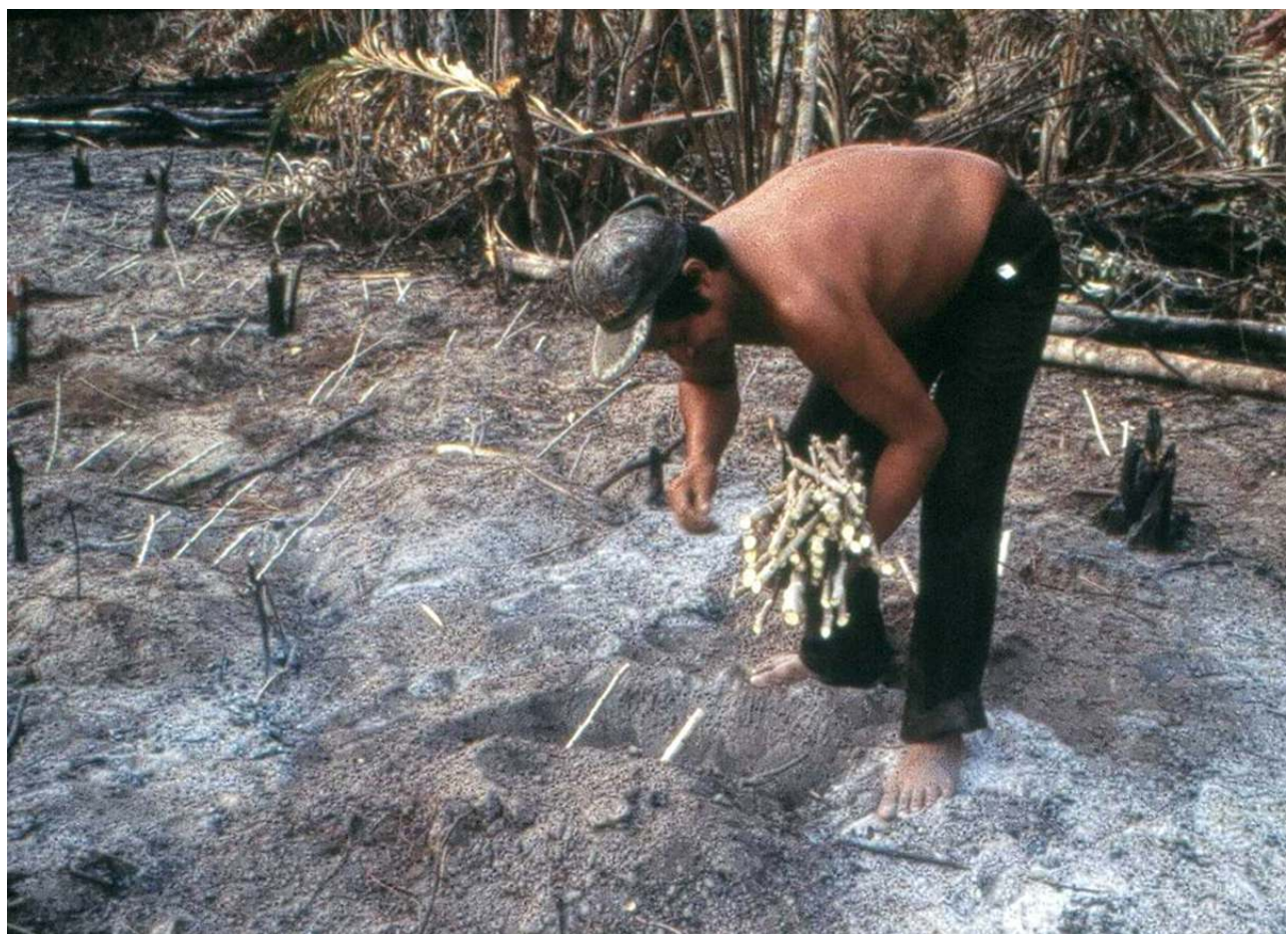

(Photo Doyle McKey)

La propagation clonale ne génère pas de variation - à l'exception des mutations somaclonales. De plus, à chaque récolte, du fait du hasard ou de la sélection, certains individus fourniront plusieurs boutures, et d'autres, aucune. En conséquence, seul un nombre réduit de plantes et donc une partie seulement de la diversité génétique, sert de 
base à la constitution du champ suivant. La propagation clonale, si elle est pratiquée de façon exclusive, conduit alors à la perte, peut-être lente mais inéluctable, de la diversité génétique.

\section{Pourquoi propager une plante domestiquée par bouturage et non par voie de graine?}

15 Face à un tel inconvénient, pourquoi les cultivateurs persistent-ils à propager la plante par voie clonale? La propagation par bouturage présente d'énormes avantages agronomiques. Premièrement, elle permet la multiplication de génotypes favorables. Le manioc, comme la plupart des plantes domestiquées propagées par voie clonale, est fortement allogame, c'est-à-dire qu'il possède des adaptations favorisant les croisements avec d'autres individus (Zohary 2004). D'autres cultures à propagation clonale, comme l'igname (dioïque) et la patate douce (auto-incompatible) sont obligatoirement allogames; le manioc, quant à lui, est préférentiellement allogame, mais capable d'autofécondation si l'allopollen n'est disponible qu'en quantité limitante. Le système de reproduction du manioc (et de ses parents sauvages) présente de forts contrastes avec celui qui caractérise la plupart des plantes domestiquées propagées par graines, telles que les céréales et les légumineuses. Ces dernières sont plutôt autogames, favorisant l'autofécondation. Chez ces espèces, une plante montrant un trait utile aux cultivateurs peut être croisée avec elle-même pour produire toute une lignée familiale présentant le même trait. Par contre, les plantes allogames, telles que le manioc, ne sont pas « conformes au type »: leurs descendants expriment souvent des phénotypes très divers, reflétant le fait que leur patrimoine génétique provient non seulement de leur mère, mais aussi pour moitié d'un ou de plusieurs pères, souvent peu apparentés. Chez ces plantes, la propagation clonale est le seul moyen d'être sûr de reproduire le phénotype recherché, c'est-à-dire la seule façon efficace de multiplier une plante portant des traits intéressants pour les cultivateurs.

Un deuxième avantage de la propagation clonale est que la bouture contient beaucoup plus de réserves qu'une graine, ce qui entraîne un développement plus rapide de la plante. Finalement, chez le manioc la propagation clonale permet d'obtenir plus de tubercules, car à chaque nœud souterrain de la tige bouturée peuvent se former plusieurs racines adventices qui se tubérisent.

\section{... mais la propagation clonale a des inconvénients ...}

La propagation clonale a cependant des inconvénients. Les clones ne sont pas immuables : ils peuvent être perdus par hasard et peuvent accumuler des mutations. Certaines de ces mutations sont neutres, n'influençant pas la valeur sélective de la plante. D'autres ont un effet négatif, d'autres encore un effet positif. Les mutations ayant un effet négatif sur la plante semblent être beaucoup plus fréquentes que les mutations bénéfiques. La plante accumule donc de plus en plus de mutations délétères avec le temps.

Ce processus, appelé « cliquet de Muller » (Felsenstein 1974), conduit à la diminution des performances (et de la qualité agronomique) du clone avec le temps. De plus, lorsque la propagation est purement clonale, il n'y a aucun mécanisme qui permette de combiner les différentes mutations bénéfiques qui ont pu se produire dans différentes lignées clonales. 
Les plantes portant ces mutations favorables sont donc en situation de compétition. Le brassage sexué permet de remédier à ces deux contraintes. Parmi l'énorme diversité de génotypes produits par la recombinaison, ceux qui combinent plusieurs mutations bénéfiques sont favorisés par la sélection, et ceux qui renferment le plus grand nombre de mutations délétères peuvent être éliminés. En permettant d'éliminer la plupart des mutations délétères et de combiner différentes mutations favorables, afin qu'elles coopèrent au sein d'un même individu au lieu d'être en compétition, la reproduction sexuée permet une évolution beaucoup plus rapide que la reproduction strictement clonale (« mécanisme Fisher-Muller » [Fisher 1930 ; Muller 1932]).

19 La propagation clonale conduit également à un autre problème: l'accumulation de pathogènes. Les propagules clonales - morceaux de tiges, de cormes, de tubercules portent souvent sur leur surface (ou dans le sol associé) des nématodes, des cochenilles ou d'autres ravageurs; ou portent dans leurs tissus des pathogènes systémiques tels que des maladies virales, fongiques ou bactériennes. Ces maladies peuvent s'accumuler, tout au long de la vie d'une lignée clonale (Lozano \& Nolt 1989), par un processus qui ressemble à un « cliquet de Muller » ultra-rapide.

Elles peuvent aussi être transmises d'une plante infectée à des plantes non infectées, par exemple lorsque la même machette est utilisée pour préparer les boutures. L'accumulation de pathogènes systémiques est un problème agronomique affectant non seulement le manioc, mais aussi de nombreuses autres plantes domestiquées propagées par voie clonale.

21 Ces problèmes phytosanitaires sont beaucoup moins sensibles chez les plantes propagées par voie de graine, car la surface des graines est souvent beaucoup plus propre que celle des propagules végétatives, et car leurs conditions de stockage éliminent les éventuels ravageurs. De plus, la plupart des maladies systémiques ne passent pas la barrière placentaire. Ainsi, une plante infectée produit des graines non infectées (Lozano \& Nolt 1989).

\section{Comment associer les deux types de propagation pour maintenir le potentiel adaptatif du manioc?}

Pour résumer, malgré ses avantages agronomiques, la propagation clonale, si elle est pratiquée à l'exclusion du brassage sexué, conduit à deux problèmes : la diminution de vigueur des clones au cours du temps, liée à l'accumulation de mutations délétères mais aussi - et sans doute majoritairement - à l'accumulation de maladies systémiques et autres pathogènes; et la perte de clones, donc de la diversité génétique et du potentiel adaptatif de la population. Maintenir ce potentiel est pourtant crucial, parce que les génotypes adaptés aux conditions actuelles ne sont pas forcément ceux qui seront adaptés aux environnements futurs. Comment remédier à ce problème?

La solution idéale consisterait à inclure un peu de reproduction sexuée dans le cycle reproducteur de la plante, pour injecter de la diversité génétique. Mais la mise en œuvre n'est pas si simple, car la propagation clonale peut créer des populations dont la structuration génétique favorise les croisements consanguins. Parce que le manioc est sensible à la dépression de consanguinité, les plantes issues d'une telle reproduction sexuée verraient alors leur vigueur et leur intérêt agronomique diminués. Comment contourner ce désavantage? En effet, le but même de la propagation clonale est de 
multiplier les génotypes ayant des caractéristiques très favorables à une fréquence élevée dans la plantation. Un champ risque donc de contenir de nombreux pieds de manioc à génotype identique, ou très proches génétiquement les uns aux autres. De plus, comme nous verrons plus tard, les Amérindiens plantent souvent leurs champs en taches monovariétales. Un pied de manioc risque ainsi d'être entouré par de nombreux individus génétiquement très proches ou identiques. Le manioc est pollinisé par des insectes qui vont d'habitude de proche en proche parmi les plants de manioc. Cette proximité d'individus génétiquement très proches ou identiques va conduire à une forte proportion de croisements consanguins.

Or, chez les organismes préférentiellement allogames comme le manioc, les individus résultant de croisements consanguins ont souvent une valeur sélective réduite : dans les populations où les croisements allogames prédominent habituellement, la plupart des allèles délétères récessifs ne peuvent être éliminés par la sélection. Comme ces allèles sont rares dans la population globale, presque tous les individus qui les portent sont hétérozygotes. L'effet de l'allèle délétère récessif est alors caché par un allèle dominant fonctionnel, qui rend l'allèle délétère "invisible» aux mécanismes de sélection. Cependant, plus deux individus sont apparentés, plus la probabilité qu'ils partagent les mêmes mutations délétères est grande. Les croisements consanguins (et a fortiori, l'autofécondation, ou la geitonogamie, c'est-à-dire les croisements entre deux clones identiques) ont donc une forte probabilité d'engendrer des individus homozygotes pour un ou plusieurs allèles récessifs délétères qui seront alors exprimés. Ces individus consanguins souffrent alors de " dépression consanguine ", c'est-à-dire d'une diminution de leur valeur sélective à cause des effets délétères de ces allèles récessifs. Dans des populations dont la structure donne ainsi naissance à une forte proportion de croisements consanguins, une fraction considérable des individus issus de la reproduction sexuée risque donc de présenter un intérêt agronomique quasiment nul. Cette situation pourrait encourager les cultivateurs à considérer les plantes issues de graines comme n'étant pas dignes d'intérêt, et à dépendre encore plus exclusivement de la propagation clonale. On se retrouve donc face à un cycle de rétroactions positives où la propagation clonale produit un système de croisements plus consanguins, qui conduit à son tour à l'augmentation de la dépression consanguine, renforçant la dépendance à la propagation clonale.

À long terme, la diminution de l'importance de la sexualité dans le cycle reproducteur de la plante peut entraîner une réduction de la fertilité sexuelle. C'est peut-être un tel processus qui peut expliquer, au moins en partie, pourquoi certaines plantes domestiquées (par exemple, le bananier, le kava, et certaines ignames) propagées par voie clonale ont perdu leur fertilité sexuelle. Chez ces plantes, la propagation clonale a conduit non seulement à la réduction de la diversité génétique, mais aussi à plus long terme à la perte, partielle ou totale, du mécanisme même pouvant générer de la diversité.

\section{Comment les Amérindiens obtiennent-ils une grande diversité génétique?}

Qu'en est-il du manioc et de la diversité génétique des populations gérées par les Amérindiens ${ }^{7}$, qui ont domestiqué cette plante il y plus de 7000 ans ? S'ils parviennent à cultiver cette plante, de façon apparemment durable, depuis plusieurs milliers d'années, 
ils doivent certainement avoir trouvé des solutions aux contraintes particulières imposées par la propagation clonale.

Quand on se promène dans une plantation amérindienne (Photo 4), on s'aperçoit que les populations de manioc renferment une grande diversité phénotypique (caractères observables), évidente dans l'architecture des plantes (certaines sont très ramifiées, d'autres peu), la taille et la forme des feuilles (variant de simples à palmatilobées, comportant jusqu'à onze lobes foliaires), la forme des racines (racines tubérisées sessiles à pédonculées) et les multiples couleurs qui caractérisent tous ces organes.

Photo 4. Parcelle d'agriculture itinérante sur brûlis

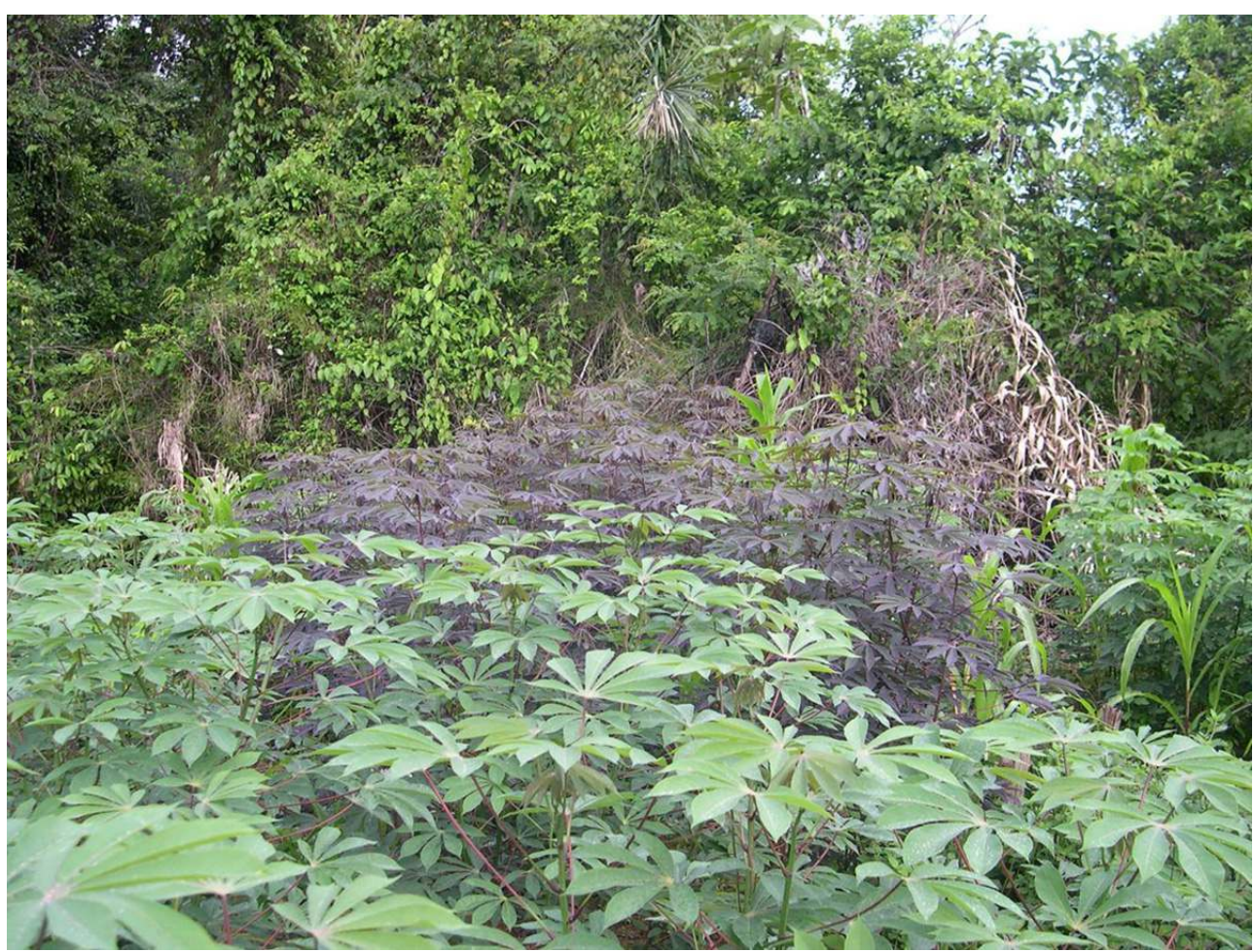

Une parcelle d'agriculture itinérante sur brûlis (" abattis ») chez les Amérindiens Wayãpi, montrant au moins trois variétés, différant par la couleur des feuilles (de l'avant-champ à l'arrière-champ, vert clair, violet, vert foncé)

(Photo Anne Duputié)

Comment expliquer cette diversité, face aux contraintes liées à la propagation clonale ? Cette diversité morphologique correspond-elle à une diversité génétique ? Pour répondre à cette question, Marianne Elias (Elias et al. 2000a) a examiné la diversité génétique des populations de manioc cultivées dans un village Makushi en Guyana, où elle avait relevé la présence de 76 variétés différentes nommées. Pour 31 de ces variétés, dont elle a évalué la différenciation morphologique (Elias et al. 2000b), elle a étudié la structure de la diversité génétique dans le détail, utilisant des marqueurs AFLP, qui sont des marqueurs moléculaires hypervariables servant à caractériser la diversité génétique au sein des populations. Elle a caractérisé génétiquement quatre ou cinq individus récoltés dans différents champs pour chaque variété. La figure 1 montre les principaux résultats de son analyse. 
Figure 1. Structuration de la diversité génétique chez les variétés locales de manioc dans le village Makushi de Rewa, révélée par des marqueurs aflp

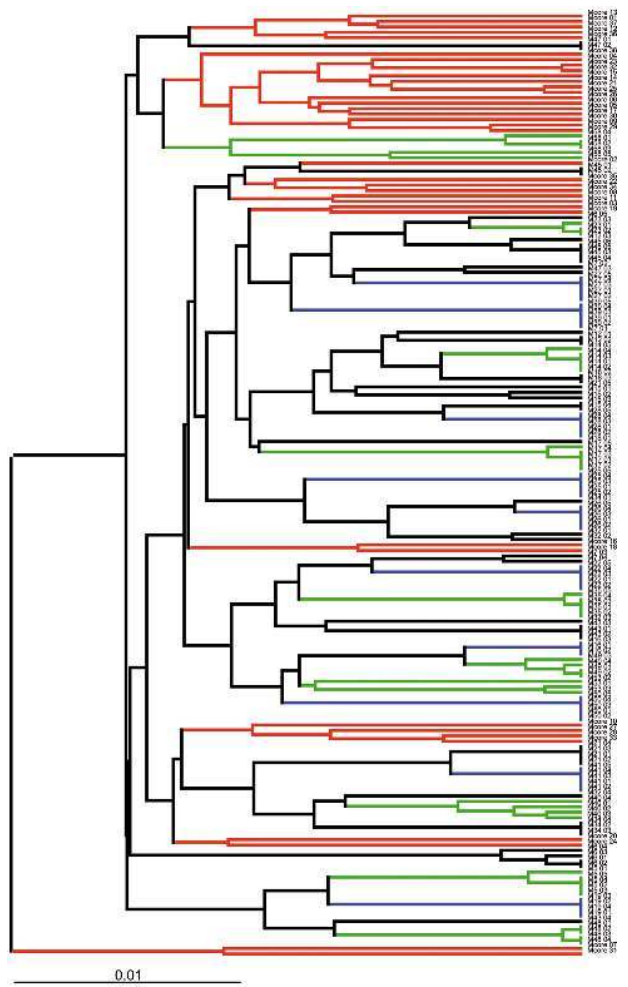

Les codes de chaque individu échantillonné apparaissent dans la colonne à droite de la figure et les distances génétiques entre les individus sont proportionnelles aux longueurs des branches du dendrogramme. Pour certaines variétés locales (traits en bleu), chacun des quatre ou cinq individus échantillonnés présentaient le même génotype (indiqué par la barre verticale liant ces individus génétiquement identiques); ces variétés peuvent donc être monoclonales. Pour d'autres variétés (traits en vert), les individus échantillonnés se révélaient génétiquement proches les uns des autres : ces variétés sont polyclonales mais génétiquement assez homogènes. Finalement, d'autres variétés encore (traits en noir) étaient non seulement polyclonales mais aussi génétiquement hétérogènes. Au moins deux tiers des variétés sont polyclonales. La diversité génétique représentée dans ce seul village amérindien est comparable à celle de la collection ex situ mondiale du ciat (traits en rouge). Adapté de Elias et al. (2000b)

L'examen du dendrogramme montre plusieurs résultats remarquables. Premièrement, la diversité génétique représentée par ces variétés est considérable. À des fins de comparaison, elle a aussi étudié la diversité génétique d'un échantillon de taille comparable pris au sein de la collection ex situ de manioc maintenue au CIAT (Centre International d'Agriculture Tropicale, Calí, Colombie), dont la vocation est la conservation de la diversité génétique et morphologique du manioc au niveau mondial. Le dendrogramme montre que la diversité génétique présente dans un seul village amérindien est comparable à celle des variétés provenant de cette collection ex situ mondiale, voire plus grande: les individus provenant du village sont éclatés dans le dendrogramme, tandis que la plupart des individus de la collection mondiale sont groupés dans une seule partie du dendrogramme. Deuxièmement, plus des deux tiers des variétés ne sont pas strictement monoclonales. Cela veut dire qu'une variété n'est pas un clone, comme on aurait pu supposer, mais un groupe d'individus (parfois génétiquement apparentés, parfois non) partageant tous un phénotype similaire. 

cycle reproducteur de la plante. Par une approche liant la génétique, l'écologie, l'agronomie et l'ethnobiologie, nous avons montré que la diversité des maniocs dans ce village Makushi n'était pas le simple résultat de la propagation clonale, suivie de l'accumulation de mutations somatiques, mais résultait d'un système mixte, où le brassage sexué génère continuellement de nouveaux génotypes recombinants, incorporés par les cultivateurs dans le stock de clones propagés (Elias et al. 2000a, b; 2001a, b). Des plants de manioc issus de graines apparaissent fréquemment dans leurs champs (Photo 5). Il ne s'agit pas de maniocs « sauvages " ${ }^{9}$, mais bien de plantes spontanées issues de graines produites par leurs variétés de manioc domestiqué.

Photo 5. Un plant de manioc issu de graine

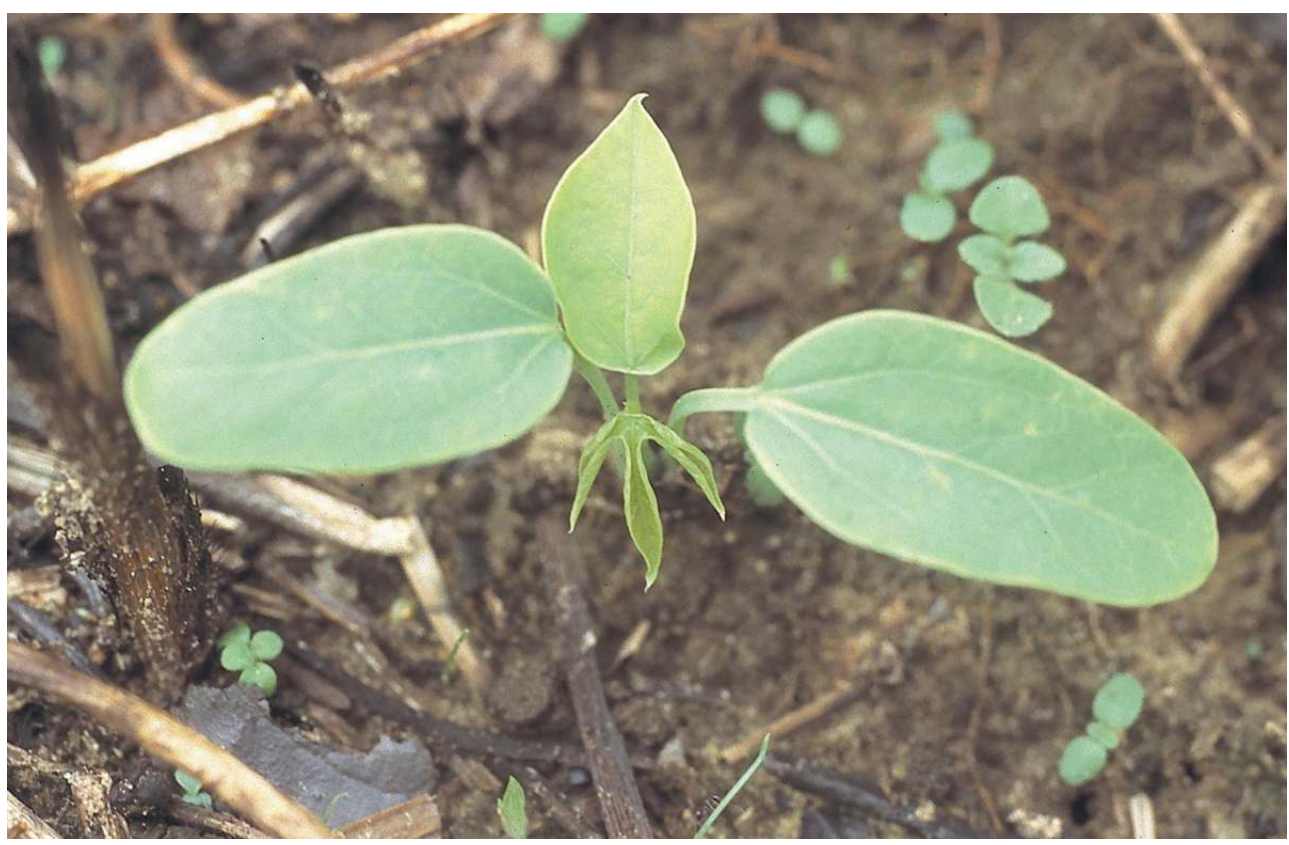

Les deux feuilles cotylédonaires caractérisant les très jeunes plantules

(Photo Doyle McKey)

Les cultivateurs Makushi connaissent l'origine de ces plantes et expriment un intérêt vif à leur égard, les observant et les laissant pousser dans leurs champs. Lors de la récolte, celles qui sont arrivées à maturité et dont les traits sont évalués favorablement par les cultivateurs, sont susceptibles d'être utilisées pour préparer des boutures. L'intérêt des cultivateurs pour les plantes issues de graines relève d'une approche véritablement expérimentale: en effet, une plante issue de graine n'est pas agronomiquement intéressante dans l'immédiat, car elle ne produit qu'une racine pivotante susceptible d'être tubérisée. Elle est donc beaucoup moins productive qu'une plante issue de bouture, qui porte à chaque nœud souterrain de la bouture des racines adventices tubérisées. La plante issue de graine est jugée d'abord sur sa vigueur et sur la qualité de sa racine, pas sur sa production. Les cultivateurs savent que la productivité d'une plante issue de graine ne peut être jugée que lors des premières générations clonales. Le plus souvent, un nouveau clone recombinant est assimilé (souvent après une période d'essai) à une variété déjà existante à laquelle il ressemble morphologiquement. Plus rarement, une plante

Revue d'ethnoécologie, 1 | 2012 
recombinante est jugée suffisamment différente pour être multipliée séparément des autres, recevoir un nouveau nom et être traitée comme nouvelle variété.

Cependant, comme nous l'avons souligné ci-dessus, combiner la propagation clonale et la reproduction sexuée n'est pas une simple affaire. Dans une population marquée par la multiplication à haute fréquence de quelques génotypes sélectionnés, une forte proportion de graines risque de provenir de croisements consanguins, et ce d'autant plus que la plantation se fait souvent en taches monovariétales (Fig. 4). L'incorporation de nouveaux génotypes recombinés doit donc être très sélective.

\section{L'écologie reproductive du manioc, héritage de son ancêtre sauvage}

Avant de se pencher sur la question de la sélection des plantules, il fallait comprendre plus en détail l'écologie de la reproduction sexuée du manioc. C'est le travail de thèse de Benoît Pujol qui a traité ces deux questions. Il s'est d'abord penché sur l'écologie comparée de la reproduction sexuée du manioc domestiqué et de son progéniteur sauvage, et, à la lumière de ces résultats, il a étudié de façon détaillée le fonctionnement démographique et génétique des populations du manioc gérées par les cultivateurs Palikur de Guyane française. La figure 2 représente le cycle de vie du manioc domestiqué, tel qu'il a été décrit au cours d'études chez les Makushi (Elias et al. 2000a), les Palikur (Pujol et al. 2005a) et les Wayãpi (Duputié et al. 2009). Bien que moins complètes, les descriptions publiées pour d'autres ethnies amérindiennes indiquent la généralité de ce cycle clonal/sexué (Boster 1984 ; Salick et al. 1997) ${ }^{10}$.

Figure 2. Cycle de vie du manioc domestiqué

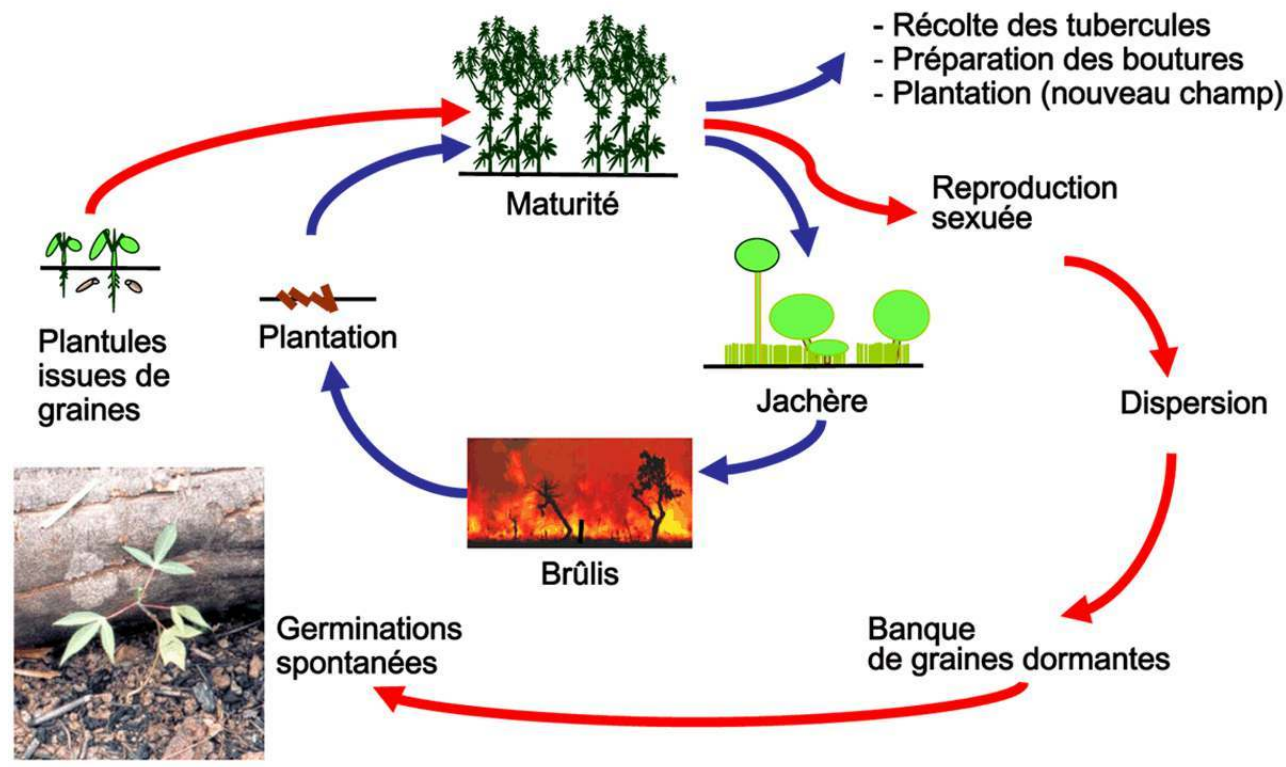

Imbrication des sous-cycles clonal (en bleu) et sexué (en rouge).

Schéma fondé sur le travail de tous les auteurs.

Tout comme d'autres cultivateurs amérindiens du manioc, les Indiens que nous avons étudiés pratiquent un système d'agriculture itinérante sur brûlis, c'est-à-dire un système 
où la culture tourne entre différentes parcelles, chacune étant utilisée pendant deux ou trois ans, puis abandonnée et laissée en jachère. La durée de la jachère est variable, entre 10 et 25 ans, voire plus (on assiste souvent aujourd'hui à un raccourcissement de cette période). La forêt secondaire est d'abord coupée, durant la saison sèche. La végétation séchée est ensuite brûlée; les cendres fournissent les nutriments qui permettront aux cultivateurs d'effectuer une (voire deux) cultures avant d'abandonner la parcelle de nouveau. La parcelle ainsi nettoyée est plantée avec des boutures de manioc au début de la saison humide. Ces plantes poussent jusqu'à maturité (généralement 18 mois et jusqu’à deux ans chez les Palikur, mais il existe aussi des variétés très précoces [9 mois]). Lors de la récolte des tubercules, qui s'étale tout au long de l'année - les cultivateurs plantant un abattis chaque année, avec des variétés à cycle plus ou moins long - , les cultivateurs sélectionnent les boutures pour la plantation de la prochaine parcelle, et l'ancien champ retourne en jachère.

Nos études ont mis en lumière une autre dimension de la biologie de reproduction du manioc sous gestion amérindienne. Juste après la plantation des boutures, des maniocs issus de graines apparaissent en grand nombre. Ces graines ont été produites par les plantes lors du précédent cycle de culture de la parcelle. Puis elles sont restées dormantes durant toute la jachère, pour germer après les perturbations liées au nettoyage et au brûlis de la nouvelle parcelle (Pujol et al. 2002, Pujol et al. 2007). Les Amérindiens laissent pousser ces plantes issues de graines, qui sont perçues comme des cadeaux de leurs ancêtres. Les cultivateurs savent que ces plantes sont issues de graines produites par les plantes du cycle de culture précédent. Ils sont également conscients du fait qu'une plante issue de graine peut parfois montrer un phénotype quelque peu différent de ceux de leurs variétés nommées. Ils sont donc assez intéressés par ces plantes spontanées, mais n'effectuent aucune intervention pour améliorer leur croissance ou leur survie: ils les laissent simplement pousser. Certaines parviennent jusqu'à maturité. Si le cultivateur évalue favorablement leurs traits, ces plantes issues de graines peuvent être utilisées pour préparer des boutures.

Les plants de manioc (qu'ils soient issus de boutures ou de graines) ont d'habitude amplement le temps de fleurir et produire des fruits et des graines, avant d'être récoltés, parce qu'ils sont souvent laissés en terre pour une période variable après leur maturité (le "stockage sur pied»). Les fleurs sont pollinisées par des insectes; les abeilles méliponines (abeilles sociales, sans dard) sont parmi les visiteurs les plus fréquents que nous avons observés. Les graines sont disséminées et constituent une banque de graines dormantes dans le sol, où elles resteront pendant toute la jachère. Leur germination est déclenchée par le brûlis (Pujol et al. 2002). La dissémination, la dormance et la germination des graines seront présentées dans le détail plus loin.

C'est l'incorporation des plantes issues de la reproduction sexuée du manioc qui, combinée à un vaste réseau d'échange de boutures (McKey et al. 2001), explique la grande diversité génétique des populations de manioc gérées par les cultivateurs amérindiens. L'étude de l'écologie reproductive de ces populations par Benoît Pujol a montré comment ce système mélange habilement la reproduction sexuée et la propagation clonale. Cette étude a en même temps ouvert une autre question : quelle est l'origine de ce système?

Pour y répondre, il a fallu s'intéresser à l'étude comparée du manioc et de ses parents sauvages. Des études moléculaires identifient comme l'ancêtre sauvage du manioc les populations de M. esculenta subsp. flabellifolia (Pohl) Ciferri du sud-ouest du bassin amazonien (états brésiliens de Rondônia et Acre) (Olsen \& Schaal 1999, 2001 ; Olsen 2004 ; 
Léotard et al. 2009). Ce taxon est aussi présent dans les Guyanes, où il est connu sous les synonymes M. surinamensis Rogers \& Appan, M. marajoara Huber et M. tristis Muell. Arg. (Allem 1994). Nous avons étudié la biologie de cette plante pour creuser les racines (évolutives, cette fois-ci) du manioc domestiqué. En fait, la stratégie écologique de l'ancêtre sauvage s'avérait être la clé pour comprendre le cycle biologique du manioc domestiqué.

Les parents sauvages du manioc, que nous avons étudiés en Guyane et également dans l'ouest du Brésil, sont des plantes inféodées aux perturbations. Ces plantes habitent l'écotone entre forêt et savane, c'est-à-dire la limite entre ces deux types de biomes. C'est un milieu très dynamique. Les perturbations fréquentes, notamment les incendies, ouvrent le milieu. La végétation subit ensuite une succession écologique, vers des milieux plus fermés - jusqu'à la prochaine perturbation. Les parents sauvages du manioc sont adaptés à ce milieu dynamique. Leurs graines germent après une perturbation qui ouvre le milieu, et ces plantes poussent rapidement lors des stades précoces de succession (Pujol et al. 2002). Leurs racines tubéreuses servent de réserves, assurant la régénération si une nouvelle perturbation vient détruire leurs appareils aériens. Dans des milieux bien ensoleillés la plante est un arbuste buissonnant, produisant de nombreuses fleurs. Quand la végétation se ferme, le manioc sauvage adopte un port lianescent, persistant ainsi durant quelques années dans les forêts secondaires. Cependant, si aucune perturbation ne se produit, il finit par disparaître - à l'exception des graines dormantes se trouvant dans le sol. Ce sont ces graines qui vont germer lorsque se produira une nouvelle perturbation.

\section{... des graines disséminées par les fourmis, non sans conséquences}

D'où vient cette banque de graines dans le sol ? La dissémination des graines du manioc sauvage se déroule en deux étapes. La première phase est autochore. Les fibres ligneuses de la capsule sont disposées de façon à ce que lorsque le fruit mature se dessèche, il subisse une déhiscence violente. La capsule « explose », projetant ses trois graines au sol, à des distances qui peuvent atteindre quelques mètres. Puis advient la deuxième phase, celle de la myrmécochorie. Chaque graine porte un petit corps lipidique, l'élaïosome (appelé «caroncule» chez les Euphorbiacées, dont fait partie le manioc), qui attire les fourmis (Elias \& McKey 2000). De par sa composition chimique, l'élaïosome ressemble à un insecte mort. Les fourmis attirées sont donc des fourmis carnivores et charognardes, qui s'intéressent uniquement à l'élaïosome et non pas à la graine. Une espèce de fourmi en particulier, Ectatomma brunneum F. Smith, est le principal disséminateur dans les populations de manioc sauvage (Renard et al. 2010) (Photo 6). Les fourmis ne montrent aucune réponse à des graines dont l'élaïosome a été manuellement enlevé. Et quand une fourmi trouve une diaspore (c'est-à-dire la propagule, formée de la graine et de l'élaïosome) de manioc sauvage, elle essaie d'abord d'enlever l'élaïosome, pour éviter de transporter la graine, qui est lourde et qui n'a aucun intérêt alimentaire pour la fourmilière. 
Photo 6. Ouvrière d'Ectatomma brunneum portant une diaspore de Manihot, Guyane française

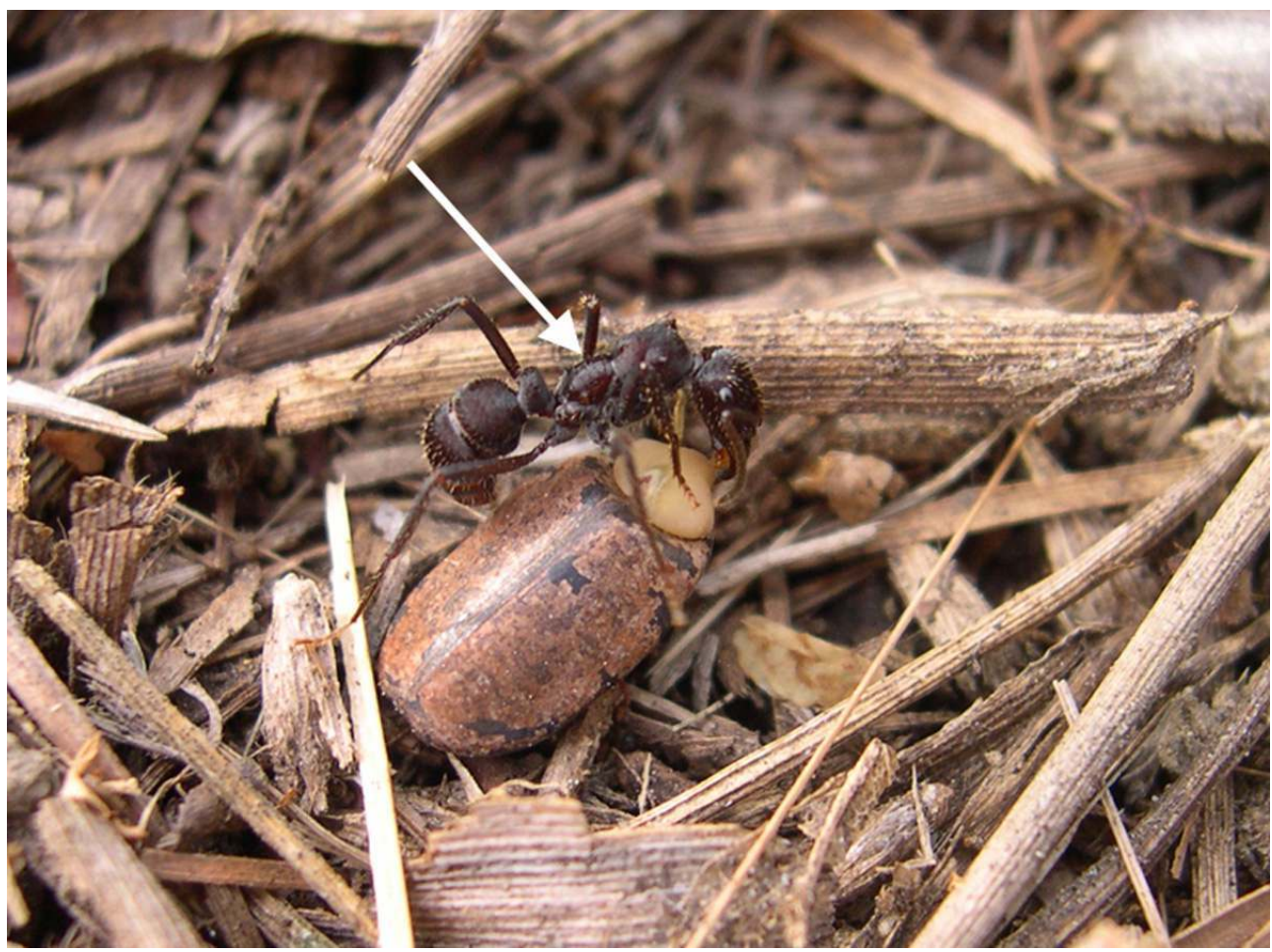

(Photo Doyle McKey)

41 L'élaïosome est cependant fermement attaché à la graine et la fourmi finit par porter la diaspore intacte, élaïosome et graine, jusqu'au nid. L'élaïosome est consommé et au cours du temps les graines, maintenant démunies d'élaïosome, sont transportées, comme les autres déchets, à la « poubelle » se trouvant près de l'entrée du nid (Renard et al. 2010). Ce sont donc les poubelles des nids de fourmis qui servent de jardin aux plantules du manioc sauvage. Dans ces microsites riches en matière organique, les graines se trouvent suffisamment proches de la surface du sol pour germer, mais elles sont suffisamment enterrées pour être protégées des prédateurs, comme les rongeurs et oiseaux granivores. On trouve souvent des amas de plantules de manioc dans les anciennes poubelles d' Ectatomma brunneum (Renard et al. 2010).

42 La stratégie de germination des graines du manioc sauvage est également adaptée au milieu dynamique de l'écotone forêt-savane. Héliophile, le manioc aura une chance de succès uniquement si la graine germe dans des milieux ouverts. Mais comment la graine peut-elle percevoir l'ouverture du milieu, si elle est enterrée ? Les graines de manioc ont un mécanisme de dormance physiologique répondant non pas à la lumière, mais à la température, comme signal de l'état de la couverture végétale. À des températures proches de $25^{\circ} \mathrm{C}$ - température typique des sols sous forêt à basse altitude dans les régions tropicales - les graines restent dormantes. Si la température dépasse $35^{\circ} \mathrm{C}$ - indiquant le réchauffement du sol suite à la disparition de la couverture végétale - les graines germent, si les conditions hydriques sont favorables (Pujol et al. 2002).

Armés de cette compréhension de l'écologie de l'ancêtre sauvage, nous pouvons maintenant comprendre l'origine $\mathrm{du}$ système amérindien de gestion $\mathrm{du}$ manioc domestiqué lui-même. En effet, le complexe d'adaptations du manioc sauvage pour la dissémination, la dormance et la germination des graines fonctionne de façon très 
similaire dans les populations de manioc domestiqué gérées par les cultivateurs amérindiens. On trouve ainsi les mêmes insectes pollinisateurs et les mêmes fourmis disséminatrices de graines dans les milieux naturels et les champs amérindiens de manioc. L'alternance jachère-brûlis fournit un contexte écologique analogue à la dynamique de l'écotone forêt-savane, et le cycle biologique du manioc sauvage est en quelque sorte « pré-adapté » à l'agriculture itinérante sur brûlis.

\section{... la stratégie amérindienne d'incorporation de nouveaux génotypes}

On voit maintenant clairement quels processus conduisent à l'apparition, dans les nouvelles plantations, de nombreux plants de manioc issus de graines. Revenons maintenant à la question posée plus tôt: comment les cultivateurs amérindiens sélectionnent-ils les plantes issues de graines, qui vont être assimilées comme nouveaux clones, de façon à ce que la diversité génétique de la population soit maintenue, sans que la qualité agronomique de leurs variétés soit diminuée ? Comme exposé plus haut, la propagation clonale peut conduire à un régime de reproduction consanguin. Les plantes issues de graines risquent dans ce cas de souffrir de la dépression consanguine, et d'être de qualité agronomique médiocre. Les marqueurs moléculaires de type microsatellite ouvrent la voie pour aborder cette question. Comme les AFLPs, ces marqueurs sont hypervariables, donc capables de détecter la diversité génétique à une échelle fine. À la différence des marqueurs AFLPs, les microsatellites sont co-dominants, c'est-à-dire que les deux allèles présents à chaque locus (celui provenant de la mère et celui provenant du père) peuvent être détectés. Si chaque individu peut être génotypé pour un nombre suffisant de loci sur différents chromosomes, le taux d'hétérozygotie donne une indication du type de croisement dont il résulte: les individus produits par croisements consanguins auront un fort taux d'homozygotie, tandis que les individus provenant de croisements allogames (père et mère non apparentés) seront hétérozygotes à une grande proportion de leurs loci. Bien que ces marqueurs soient sélectivement neutres, ils renseignent sur le taux d'hétérozygotie dans l'ensemble du génome - y compris aux loci où la condition homozygote pour des allèles délétères récessifs conduit à une dépression consanguine. Ceci permet de poser les questions suivantes: Le régime de reproduction dans les plantations de manioc conduit-il réellement à un régime de reproduction consanguin? La vigueur des individus est-elle fonction de leur hétérozygotie? L'incorporation des plantes issues de graines est-elle sélective par rapport au niveau de consanguinité?

Les variétés locales des maniocs Palikur sont caractérisées par une très forte hétérozygotie (Pujol et al. 2005a). Ce même résultat avait déjà été trouvé pour les variétés des maniocs Makushi (Elias et al. 2001b), et ceci est vrai de la plupart des variétés cultivées actuellement dans le monde, en Amazonie (Elias et al. 2004) comme en Afrique (Fregene et al. 2003). Les clones les plus populaires, qui sont multipliés et transmis de génération en génération, sont ceux qui souffrent très peu de la dépression consanguine. Cette fréquence élevée d'individus fortement hétérozygotes illustre l'un des avantages de la propagation clonale. Dans une population à reproduction purement sexuée, les génotypes sont "cassés » et "reconstruits » à chaque génération; deux hétérozygotes qui se croisent donneront naissance à une descendance variée d'hétérozygotes et d'homozygotes. Par contraste, la propagation clonale permet de maintenir quelques 
clones très favorables à des fréquences élevées. Mais qu'en est-il de l'hétérozygotie de leurs descendants par voie sexuée, les graines qui rejoindront la banque de graines dans le sol, qui pousseront lors du prochain cycle de culture, et dont l'incorporation maintiendra la diversité de la population? Le génotypage des graines produites par les clones fréquents (qui sont hétérozygotes) montre en effet que le régime de reproduction est consanguin: les graines sont beaucoup moins hétérozygotes que leurs parents. En effet, les cultivateurs amérindiens ont l'habitude de planter leurs maniocs dans des taches monovariétales : des individus génétiquement proches, voire identiques, se trouvent donc à proximité dans le champ, facilitant les transferts de pollen consanguin.

Cependant, chaque champ renferme des taches de plusieurs variétés, chacune bien différenciée des autres. Les croisements intervariétaux - effectués par des insectes volant d'une tache à une autre - devraient donc produire des individus fortement hétérozygotes. La cohorte de graines devrait donc présenter une grande variance dans le taux de consanguinité. Une grande diversité s'ouvre ainsi à la sélection.

L'incorporation de plantes issues de graines comme nouveaux clones est en effet hautement sélective, comme Benoît Pujol a pu le montrer par le suivi, du début à la fin d'un cycle de culture, des cohortes de plantes issues de graines dans deux champs Palikur (Pujol et al. 2005a). Tout au long du cycle de culture dans ces champs, le nombre de plantes issues de graines diminue, et leur mortalité est très sélective. Cette sélection inclut plusieurs mécanismes distincts: une sélection humaine, tout d'abord, lors du désherbage manuel des champs. Deux ou trois mois après la plantation des boutures, les champs sont envahis de mauvaises herbes, ce qui oblige les cultivateurs à les nettoyer, en enlevant ces plantes adventices. Selon leur discours, le désherbage ne concerne pas les plantes issues de graines. Bien que cela corresponde à leur perception, voire à leur intention, les faits sont quelque peu différents. Dans les deux champs, un quart et un tiers, respectivement, des plantes issues de graines avaient disparu, arrachées par le cultivateur (Pujol et al. 2005a). Cette mortalité était sélective au niveau du phénotype : les petits individus avaient une plus forte probabilité d'être arrachés que les grands. La taille des plantes (donc leur vigueur, toutes les plantes issues de graines dans un champ ayant le même âge) était elle aussi liée à leur constitution génétique: plus la plante était hétérozygote à de nombreux loci, plus elle était grande. La sélection humaine lors du désherbage manuel a donc favorisé les individus hétérozygotes issus de croisements très allogames, et plus vigoureux (Pujol et al. 2005a).

Benoît Pujol a aussi documenté une deuxième étape de sélection, qui s'effectue durant tout le cycle, mais de façon particulièrement intense durant la première année de culture. Les plantes issues de graines germent dans les anciennes poubelles de fourmis, parfois de façon solitaire mais souvent dans des amas de plantules - nous avons observé jusqu'à 32 plantules poussant dans un cercle de moins de 15 centimètres de diamètre. Dans ces groupes de plantules agrégées, la compétition est très forte. Les individus plus vigoureux, qui arrivent rapidement à une plus grande taille que les autres, doivent acquérir un avantage compétitif important. Là encore, il s'agit des individus les plus hétérozygotes, et la sélection naturelle agit dans le même sens que la sélection artificielle. En effet, l'expression de la dépression de consanguinité dépend de la densité des plantes et de l'intensité de la compétition intraspécifique (Pujol \& McKey 2006).

Deux étapes ultérieures de sélection sont également évidentes, bien que moins étudiées dans le détail. Dans les deux champs Palikur étudiés par Benoît Pujol, parmi les plantes issues de graines qui avaient survécu jusqu'à la récolte, c'étaient encore les plantes les 
plus vigoureuses, et les plus hétérozygotes, qui étaient choisies par le cultivateur pour la préparation des boutures. Cependant, à ce stade avancé dans le cycle de culture, le faible nombre de plantes issues de graines encore en vie ne permettait pas d'obtenir un résultat statistiquement significatif.

Une quatrième étape de sélection a été récemment étudiée par Anne Duputié, chez les Amérindiens Wayãpi de Trois Sauts, sur le haut Oyapock. Quand la plante issue de graine est utilisée pour préparer des boutures, le nouveau clone est soumis à une période d'essai. Ses descendants clonaux sont multipliés et gérés séparément des autres (même séparément des clones établis de la même variété nommée). Les agriculteurs gardent durant plusieurs années la mémoire de l'origine par graine de ce clone. Ces «clones de plantes issues de graines » sont moins hétérozygotes que les clones établis (c'est-à-dire, ceux dont on ne se souvient plus de leur origine par graine). Apparemment, les clones les plus hétérozygotes continuent à être favorisés lors de la période de sélection interclonale qui conditionne l'adoption définitive comme nouveau clone d'une plante issue de graine (Duputié et al. 2009).

51 Ainsi, quatre mécanismes sélectifs différents, l'un impliquant la sélection naturelle et les trois autres la sélection humaine, ont tous le même effet évolutif: ils favorisent les individus vigoureux ne souffrant pas de la dépression de consanguinité ${ }^{11}$. Au terme de ces étapes de sélection, les individus issus de graines ayant survécu ont un taux d'hétérozygotie qui se rapproche de plus en plus de celui des clones établis. C'est la nature très sélective de l'incorporation de nouveaux clones issus de graines qui explique comment les Amérindiens peuvent maintenir à la fois la performance agronomique de leurs maniocs, mais aussi la diversité génétique - donc le potentiel évolutif - pour assurer la performance agronomique si les conditions changent.

Même si des données solides font défaut, il est probable que l'incorporation de nouveaux clones issus de graines présente aussi des avantages phytosanitaires. En expliquant l'intérêt que les plantes issues de graines présentent pour eux, les cultivateurs amérindiens disent parfois qu'un clone peut devenir «fatigué », et que le passage par graine le «rajeunit» (Elias et al. 2000a). De telles observations peuvent être expliquées par l'accumulation de pathogènes systémiques dans les lignées clonales.

\section{.... le manioc a été introduit ailleurs, mais pas les savoirs ni les pratiques des Amérindiens}

Qu'en est-il maintenant de la diversité du manioc dans les régions où il a été introduit depuis la «découverte» de l'Amérique par les Européens? Bien que la plante ait été domestiquée en Amazonie, c'est en Afrique que se trouve aujourd'hui la plus grande production de manioc ${ }^{12}$. La diversité génétique est-elle maintenue dans ce continent d'introduction? On évoque souvent pour les espèces introduites le phénomène du "goulot d'étranglement", lié aux "effets fondateurs»: une population dérivée de quelques fondateurs, qui ne renferment qu'une très faible proportion de la diversité génétique de la population d'origine, peut subir une réduction importante de sa diversité génétique. Cependant, le nombre probablement élevé d'introductions indépendantes du manioc en Afrique rend improbable l'existence de forts effets fondateurs. Mais l'introduction peut être accompagnée d'un autre risque: tandis que la plante a été 
transférée au nouveau continent, les savoirs et les pratiques des Amérindiens concernant sa gestion n'y ont pas fait le voyage !

Le manioc a été importé en Afrique par les Portugais, et leur appréciation des savoirs amérindiens concernant cette plante semble avoir comporté des lacunes importantes. Même un domaine de savoir fondamental, celui concernant les procédures amérindiennes pour la détoxification du manioc, n'a pas été transféré intact en Afrique. Si les Portugais ont introduit les techniques nécessaires à la préparation de la farine de manioc (la farinha), l'usage de la couleuvre, en revanche, n'a pas diffusé en Afrique. C'est en Afrique (et dans d'autres régions d'introduction de la plante) que l'on observe le plus fréquemment des problèmes liés à la toxicité du manioc, problèmes dus à une détoxification inadéquate ou incomplète. En Amazonie, où le manioc amer est cultivé depuis des millénaires, de tels problèmes semblent absents (McKey et al. 2010a). Dans un domaine de savoir moins fondamental (au moins dans l'immédiat) tel que les pratiques concernant les plantes de manioc issues de graines, il est improbable que les connaissances des Portugais aient été mieux développées. La reproduction du manioc, pour les colons portugais qui ont introduit la plante en Afrique, se résumait probablement à la propagation de la plante par boutures.

La plupart des cultivateurs africains du manioc ont peu de connaissances sur l'utilité phytosanitaire ou la source de diversité génétique que peut représenter l'incorporation des plantes issues de graines (Manu-Aduening et al. 2005 ; Delêtre 2010). Les étudiants africains qui assistent à nos cours sur l'agrobiodiversité à Montpellier, qui connaissaient souvent fort bien le manioc, sont toujours étonnés d'apprendre la biologie de la reproduction sexuée de la plante, et le rôle que peuvent jouer les plantes issues de graines qui apparaissent spontanément dans les champs, et qu'ils ont toujours vues arracher sans arrière-pensée.

\section{... vers un système plus strictement clonal ... ou vers la (ré-)invention du savoir?}

Quelles peuvent être les conséquences de cette non-transmission de savoirs lors de l'introduction d'une plante comme le manioc, dont la bonne gestion dépend de savoirs spécialisés? Si les plantes issues de graines sont systématiquement arrachées, car considérées agronomiquement inutiles, le régime de reproduction de la plante deviendra plus strictement clonal. Si tel est le cas, quelles seront les conséquences pour la diversité génétique des populations, et pour la dynamique de pathogènes systémiques qui peuvent s'accumuler dans des lignées clonales? Une telle différence entre l'Afrique et l'Amazonie dans le régime de reproduction du manioc peut-elle contribuer à expliquer pourquoi les maladies virales du manioc semblent être plus importantes en Afrique qu'ailleurs dans le monde ? Ou bien les pratiques concernant les plantes issues de graines sont-elles en train d'évoluer en Afrique? Quelques cas, pour l'instant anecdotiques, d'expérimentation avec les plantes issues de graines de manioc sont connus en Afrique. Il est intéressant de noter que la plupart de ces observations proviennent d'Afrique orientale, où les pandémies du virus de la mosaïque du manioc ont ravagé les cultures de façon répétée, inspirant la recherche de solutions parfois peu conventionnelles. Les pratiques des cultivateurs africains concernant les plantes issues de graines de manioc, les relations entre ces pratiques et la diversité des maniocs à l'échelle locale, et la variation dans les pratiques à 
l'échelle d'un pays (le Gabon), constituent le sujet de la thèse de Marc Delêtre (Delêtre 2010). Est-ce que les agriculteurs gabonais (ré-) inventent des savoirs similaires à ceux des Amérindiens concernant l'utilisation de la reproduction sexuée? Si c'est le cas, quels facteurs favorisent l'utilisation de plantes issues de graines? Existe-t-il des «points chauds » de création variétale, et des " points froids » où la diversité est moindre ou, si elle existe, est simplement due à l'accumulation par des cultivateurs de variétés créées ailleurs?

\section{Conclusion}

Nous avons montré comment les cultivateurs amérindiens, par leur gestion habile de l'écologie de la reproduction du manioc, maintiennent à la fois la performance agronomique de leurs populations de la plante et le potentiel évolutif de la plante pour créer de nouveaux génotypes, dont certains peuvent se révéler capables d'assurer la production dans les environnements futurs. Dans les régions d'introduction du manioc, le savoir nécessaire pour cette gestion n'a pas été introduit. Bien que ce savoir puisse se réinventer, ce processus risque d'être lent. Doit-on intervenir pour favoriser cette réinvention, en montrant l'intérêt des plantes issues de graines et en suggérant des pratiques à suivre? Si elle est intégrée dans une gestion participative qui prend en compte les souhaits et les besoins des cultivateurs, elle peut être utile. Une approche nécessitant la gestion continue par chaque paysan de la reproduction de ces plantes ne peut jamais « prendre racine » si elle est conduite de façon directive, « top-down ».

Nous remercions les éditeurs de la Revue d'ethnoécologie de nous avoir invités à écrire cet article, et Françoise Aubaile, Serge Bahuchet, Jean-Marie Betsch et Sabine Hoare-Bognon pour leur assistance éditoriale durant les premières phases de sa préparation. Les recherches rapportées ici ont été financées par le programme européen l'Avenir des Peuples des Forêts Tropicales (DGVIII), par le Bureau des Ressources Génétiques, par la Mission pour la Création du Parc de la Guyane, par le programme «Écosystèmes Tropicaux» du Ministère de l'Écologie et du Développement Durable, par le programme 'Impact des Biotechnologies dans les Agroécosystèmes' du Ministère de la Recherche et de l'Enseignement Supérieur, par le Contrat Plan État Région Guyane, et par le Prix Terra Ficaria décerné à D. McKey (au nom de toute l'équipe) par la Fondation Yves Rocher/Institut de France en 2006. Marianne Elias, Benoît Pujol, Anne Duputié et Delphine Renard ont bénéficié de bourses doctorales du Ministère de la Recherche, et Marc Delêtre d'une bourse doctorale de l' IRCSET (gouvernement irlandais). Notre plus grande dette de gratitude est envers les agriculteurs qui nous ont accueillis et qui ont partagé leurs savoirs avec nous, au Guyana, en Guyane et au Gabon.

\section{BIBLIOGRAPHIE}

Allem A.C. 1994 - The origin of Manihot esculenta Crantz (Euphorbiaceae). Genetic Resources and Crop Evolution $41: 133-150$. 
Boster J.S. 1984 - Classification, cultivation and selection of Aguaruna cultivars of Manihot esculenta (Euphorbiaceae). In Prance G.T. \& Kallunki J.A. (Ed.), Ethnobotany in the Neotropics, Advances in Economic Botany, 1. Bronx, New York, New York Botanical Garden : 34-47.

Caillon S., Quero-Garcia J., Lescure J.P. \& Lebot V. 2006 - Nature of taro (Colocasia esculenta (L.) Schott) genetic diversity prevalent in a Pacific Ocean island, Vanua Lava, Vanuatu. Genetic Resources and Crop Evolution 53 : 1273-1289.

Collomb P. 1999 - Une voie étroite pour la sécurité alimentaire d'ici à 2050. Economica, 197 p. http:// www.fao.org/DOCREP/003/X3002F/X3002F00.htm (consulté le 8 juin 2004).

Delêtre M. 2010 - The ins and outs of manioc diversity in Gabon, Central Africa : A pluridisciplinary approach to the dynamics of genetic diversity of Manihot esculenta Crantz (Euphorbiaceae). Thèse de doctorat, Trinity College, Université de Dublin, Irlande.

Dickau R., Ranere A.J. \& Cooke R.G. 2007 - Starch grain evidence for the preceramic dispersals of maize and root crops into tropical dry and humid forests of Panama. Proceedings of the National Academy of Sciences USA 104 : 3651-3656.

Duputié A., Massol F., David P., Haxaire C. \& McKey D. 2009 - Traditional Amerindian cultivators combine directional and ideotypic selection for sustainable management of cassava genetic diversity. Journal of Evolutionary Biology, sous presse.

Duputié A., Salik J. \& McKey D. 2010 - Evolutionary biogeography of Manihot, a rapidly radiating Neotropical genus restricted to dry environments. Journal of Biogeography 38 : 1033-1043.

Elias M. \& McKey D. 2000 - The unmanaged reproductive ecology of domesticated plants in traditional agroecosystems : an example involving cassava and a call for data. Acta Oecologica 21 : 223-230.

Elias M., Rival L. \& McKey D. 2000a - Perception and management of cassava (Manihot esculenta Crantz) diversity among Makushi Amerindians of Guyana (South America). Journal of Ethnobiology $20: 239-265$.

Elias M., Panaud O. \& Robert T. 2000b - Assessment of genetic variability in a traditional cassava ( Manihot esculenta Crantz) farming system, using AFLP markers. Heredity 85 : 219-230.

Elias M., McKey D., Panaud O., Anstett M.C. \& Robert T. 2001a - Traditional management of cassava morphological and genetic diversity by the Makushi Amerindians (Guyana, South America) : Perspectives for on-farm conservation of crop genetic resources. Euphytica 120 : 143-157.

Elias M., Penet L., Vindry P., McKey D., Panaud O. \& Robert T. 2001b - Unmanaged sexual reproduction and the dynamics of genetic diversity of a vegetatively propagated crop plant, cassava (Manihot esculenta Crantz), in a traditional farming system. Molecular Ecology 10 : 1895-1907.

Elias M., Mühlen G.S., McKey D., Roa A.C. \& Tohme J. 2004 - Genetic diversity of traditional South American landraces of cassava (Manihot esculenta Crantz) : An analysis using microsatellites. Economic Botany 58 : 242-256.

FAO 2008 - Cassava for food and energy security. http://www.fao.org/newsroom/en/ news/2008/1000899/index.html (consulté le 23 mai 2011)

Felsenstein J. 1974 - The evolutionary advantage of recombination. Genetics 78 : 737-756.

Fisher R.A. 1930 - The genetical theory of natural selection. Oxford, Clarendon Press. 
Fregene M., Suarez M., Mkumbira J., Kulembeka H., Ndedya E., Kulaya A., Mitchel S., Gullberg S., Rosling H., Dixon A.G.O., Dean R. \& Kresovich S. 2003 - Simple sequence repeat marker diversity in cassava landraces : genetic diversity and differentiation in an asexually propagated crop. Theoretical and Applied Genetics $107: 1083-1093$.

Fregene M., Matsumura H., Akano A., Dixon A. \& Terauchi R. 2004 - Serial analysis of gene expression (SAGE) of host-plant resistance to the cassava mosaic disease (CMD). Plant Molecular Biology 56 : 563-571.

Grenand F. 1996 - Cachiri, l'art de la bière de manioc chez les Wayãpi de Guyane. In BatailleBenguigui M.C. \& Cousin F. (Ed.) Cuisines, reflets des sociétés. Sépia-Musée de l'Homme : 325-347.

Henkel T.W. 2005 - Parakari, an indigenous fermented cassava beverage utilizing amylolytic Rhizopus in Guyana. Mycologia 97 : 1-11.

IFAD/FAO 2000 - The World Cassava Economy. Facts, Trends and Outlook. FAO, Rome, Italy, 66 p. $\mathrm{ftp}: / / \mathrm{ftp}$.fao.org/docrep/fao/009/x4007e/X4007E00.pdf

Johns T. \& Keen S.L. 1986 - Ongoing Evolution of the Potato on the Altiplano of Western Bolivia. Economic Botany 40 : 409-424.

Léotard G., Duputié A., Kjellberg F., Douzery E.J.P., Debain C., de Granville J.J. \& McKey D. 2009 - Phylogeography and the origin of cassava : new insights from the northern rim of the Amazonian basin. Molecular Phylogenetics and Evolution, 53 : 329-334.

Lozano J.C. \& Nolt B.L. 1989 - Pests and pathogens of cassava. In Kahn R.P. (Ed.) Plant protection and quarantine, vol. II. Selected pests and pathogens of quarantine significance. CRC Press : 169-182.

Manu-Aduening J.A., Lamboll R.I., Dankyi A.A. \& Gibson R.W. 2005 - Cassava diversity in Ghanaian farming systems. Euphytica $144: 331-340$.

McKey D. \& Beckerman S. 1993 - Chemical ecology, plant evolution and traditional manioc cultivation systems. In Hladik C.M., Hladik A., Linares O.F., Pagezy H., Semple A. \& Hadley M. (Ed.), Tropical Forests, People and Food. Biocultural Interactions and Applications to Development, Paris, France, et Parthenon, Canforth, UK, UNESCO : 83-112.

McKey D., Cavagnaro T., Cliff J. \& Gleadow R. 2010a - Chemical ecology in coupled human and natural systems : people, manioc, multitrophic interactions and global change. Chemoecology 20 : 109-133.

McKey D., Elias M., Pujol B. \& Duputié A. 2010b - The evolutionary ecology of clonally propagated domesticated plants. New Phytologist $186: 318-332$.

McKey D., Elias M., Pujol B. \& Duputié A. 2011 - Ecological approaches to cop domestication, in Biodiversity. In Gepts P., Bettinger R., Brush S.B., Famula T., McGuire P., Qualset C.O. \& Damania A.B. (Ed.), Agriculture : Domestication, Evolution and Sustainability, Cambridge, Cambridge University Press, (sous presse).

McKey D., Emperaire L., Elias M., Pinton F., Robert T., Desmoulière S. \& Rival L. 2001 - Gestions locales et dynamiques régionales de la diversité variétale du manioc en Amazonie. Genetics Selection Evolution 33 (Suppl. 1) : S465-S490.

McMahon J.M., White W.L.B. \& Sayre R.T. 2005 - Cyanogenesis in cassava (Manihot esculenta Crantz). Journal of Experimental Botany $46: 731-741$.

Muller H.J. 1932 - Some genetic aspects of sex. The American Naturalist 66 : 118-138. 
Nhassico D., Muquingue H., Cliff J., Cumbana A. \& Bradbury J.H. 2008 - Rising African cassava production, diseases due to high cyanide intake and control measures. Journal of the Science of Food and Agriculture 88 : 2043-2049.

Olsen K.M. 2004 - SNPs, SSRs and inferences on cassava's origin. Plant Molecular Biology 56 : 517-526.

Olsen K.M. \& Schaal B.A. 1999 - Evidence on the origin of cassava : phylogeography of Manihot esculenta. Proceedings of the National Academy of Sciences USA $96: 5586-5591$.

Olsen K.M. \& Schaal B.A. 2001 - Microsatellite variation in cassava (Manihot esculenta, Euphorbiaceae) and its wild relatives : further evidence for a southern Amazonian origin of domestication. American Journal of Botany 88 : 131-142.

Piperno D.R., Ranere A.J., Holst I. \& Hansell P. 2000 - Starch grains reveal early root crop horticulture in the Panamanian tropical forest. Nature $407: 894-897$.

Pujol B., Gigot G., Laurent G., Pinheiro-Kluppel M., Elias M., Hossaert-McKey M. \& McKey D. 2002 - Germination ecology of cassava (Manihot esculenta Crantz, Euphorbiaceae) in traditional agroecosystems : seed and seedling biology of a vegetatively propagated domesticated plant. Economic Botany 56 : 366-379.

Pujol B., David P. \& McKey D. 2005a - Microevolution in agricultural environments : how a traditional Amerindian farming practice favours heterozygosity in cassava (Manihot esculenta Crantz, Euphorbiaceae). Ecology Letters 8 : 138-147.

Pujol B., Mühlen G.S., Garwood N., Horoszowski Y., Douzery E.J.P. \& McKey D. 2005b - Evolution under domestication : contrasting functional morphology of seedlings in domesticated cassava and its closest wild relatives. New Phytologist $166: 305-318$.

Pujol B. \& McKey D. 2006 - Size asymmetry in intraspecific competition and the densitydependence of inbreeding depression in a natural plant population : a case study in cassava ( Manihot esculenta Crantz, Euphorbiaceae). Journal of Evolutionary Biology 19 : 85-96.

Pujol B., Renoux F., Elias M., Rival L. \& McKey D. 2007 - The unappreciated ecology of landrace populations : conservation consequences of soil seed banks in cassava. Biological Conservation 136 : 541-551.

Renard D., Schatz B. \& McKey D. 2010 - Ant nest architecture and seed burial depth : implications for seed fate and germination success in a myrmecochorous savanna shrub. Ecoscience 17 : 194-202.

Rival L. \& McKey D. 2008 - Domestication and diversity in manioc (Manihot esculenta Crantz ssp. esculenta, Euphorbiaceae). Current Anthropology 49 :1119-1128.

Salick J., Cellinese N. \& Knapp S. 1997 - Indigenous diversity of cassava : generation, maintenance, use and loss among the Amuesha, Peruvian upper Amazon. Economic Botany 51 : 6-19.

Scarcelli N., Tostain S., Vigouroux Y., Agbangla C., Daïnou O. \& Pham J.L. 2006 - Farmers' use of wild relative and sexual reproduction in a vegetatively propagated crop. The case of yam in Benin. Molecular Ecology 15 : 2421-2431.

Zohary D. 2004 - Unconscious selection and the evolution of domesticated plants. Economic Botany $58: 5-10$ 


\section{NOTES}

1. En fait, il s'agit le plus souvent de cultivatrices. Nous utiliserons la forme masculine pour référer aux deux sexes.

2. C'est-à-dire, la Guyane française, le Surinam (ex-Guyane hollandaise), le Guyana (ex-Guyane britannique) et une partie du Vénézuela.

3. Nom Makushi ; chez les Wayãpi ; kai ; en anglais de Guyana : cassareep.

4. Ce terme, aujourd'hui répandu, dérive du mot Taino (Amérindiens d'Haïti) caçábi.

5. Nom Makushi ; chez les Wayãpi : cachiri.

6. Nom Makushi ; chez les Wayãpi kwak; couac en français de Guyane.

7. Voir aussi Rival \& McKey (2008) pour une synthèse de la gestion amérindienne du manioc.

8. Dans cet article, le mot « variété » fait référence à une " variété pays » (anglais : « landrace »), dont la définition est une unité phénotypique reconnue et nommée par les cultivateurs euxmêmes, qui la gèrent et la reproduisent séparément des autres. Les variétés diffèrent souvent (mais pas toujours) dans leurs usages, leurs exigences écologiques, leur précocité.

9. Le plus proche parent sauvage du manioc (c'est-à-dire son progéniteur), Manihot esculenta ssp. flabellifolia, est en effet lui aussi présent dans cette région (Allem 1994).

10. L'incorporation de nouveaux clones à partir de plantes issues de graines est également documentée pour plusieurs autres plantes domestiquées propagées par voie clonale (Johns \& Keen 1986 ; Caillon et al. 2006 ; Scarcelli et al. 2006).

11. La pression sélective favorisant des plantes à croissance rapide peut aussi expliquer les différences remarquables dans la morphologie des plantules du manioc et de ses plus proches parents sauvages (Pujol et al. 2005b).

12. Chacune des deux grandes régions d'introduction du manioc, l'Afrique et l'Asie, produisent aujourd'hui plus de manioc que le continent d'origine de la plante. De la production mondiale de 228 millions de $t$, l'Afrique compte pour 117,9 millions de $t$, l'Asie pour 71,8 millions de $t$ et l'Amérique du Sud pour 36,8 millions de $t$ (FAOSTAT, 2007).

\section{RÉSUMÉS}

Nous avons étudié comment les Amérindiens d'Amazonie maintiennent à la fois la performance agronomique et la diversité génétique de leurs cultures de manioc. Domestiqué en Amazonie il y a probablement plus de 7000 ans, le manioc est aujourd'hui à la base de l'alimentation de près d'un milliard de personnes. Cette plante est majoritairement reproduite par bouturage ; cette propagation clonale confère d'énormes avantages agronomiques, mais, pratiquée en excluant toute reproduction sexuée, elle peut conduire à l'appauvrissement génétique des populations domestiquées, donc à la perte de leurs capacités d'adaptation. Nous avons montré que les paysans amérindiens incorporent régulièrement des plantes issues de graines à partir d'une banque de graines dormantes dans le sol. Toutes les plantes issues de graine correspondent à de nouveaux génotypes recombinants, et leur incorporation par les cultivateurs dans le stock de boutures maintient donc la diversité génétique des populations. Cependant, le régime de reproduction du manioc dans les champs amérindiens est fortement consanguin, et les individus consanguins souffrent d'une performance agronomique très médiocre. Par l'incorporation très 
sélective des plantes issues de graines - via des processus associant sélection naturelle et artificielle - les cultivateurs amérindiens parviennent à maintenir à la fois la diversité génétique et la performance agronomique de leurs populations de manioc, en combinant reproduction sexuée et propagation clonale de façon à bénéficier des avantages des deux modes de reproduction tout en minimisant leurs inconvénients. Dans les régions où le manioc a été introduit depuis la « découverte" de l'Amérique par les Européens, les savoirs des cultivateurs amérindiens sur l'utilisation des produits de la reproduction sexuée n'ont pas été introduits avec la plante, et nous examinons les conséquences que la réinvention lente et hétérogène de ces savoirs peut avoir pour la durabilité de la contribution du manioc à la sécurité alimentaire.

We studied how Amerindian cultivators of manioc in Amazonia simultaneously maintain the genetic diversity and the agronomic performance of their populations of this plant. A shrub domesticated in Amazonia probably over 7000 years ago, manioc is today the staple food for over a billion people throughout the tropical world. It is propagated by farmers by stem cuttings : a small section of stem is cut from a mature plant and directly planted in the ground. This amounts to cloning. Cloning is the only efficient way to "capture" and multiply initially rare favourable phenotypes in habitually outcrossed plants such as manioc. However, practiced to the exclusion of sexual reproduction, clonal propagation can lead to erosion of genetic diversity of crop populations, and thus to the loss of the plant's potential to adapt to stresses such as droughts or the advent of a new pathogen. We have shown that Amerindian cultivators regularly incorporate "volunteer" plants issued from spontaneously produced seedlings into their stocks of clones. These plants are recruited from a bank of dormant seeds in the soil. Seeds of manioc can remain dormant in soil for up to several decades, germinating when a disturbance creates the open conditions favourable for establishment. Each volunteer plant from seed is a new recombinant genotype, and the incorporation of these plants by farmers in their stocks of clones maintains genetic diversity in the population. However, the mating system in manioc populations in Amerindian fields is highly inbred, and agronomic performance of inbred individuals is very low. By highly selective incorporation of volunteer plants - via processes that combine both natural and artificial selection - Amerindian cultivators are able to maintain simultaneously genetic diversity and agronomic performance of their manioc populations, combining sexual reproduction and clonal propagation in a way that reaps the benefits of each mode of reproduction while minimizing their respective disadvantages. In regions where manioc has been introduced since the "discovery" of America by Europeans, the technical knowledge of Amerindian cultivators about the use of products of manioc's sexual reproduction has not been introduced along with the plant. We examine the potential consequences of the slow and patchy reinvention of this knowledge for manioc's continued contribution to food security.

\section{INDEX}

Mots-clés : agroécologie, domestication, conservation in situ, propagation clonale, reproduction sexuée, ressources génétiques, pratiques paysannes, savoirs locaux

Keywords : agroecology, Amazonia, cassava, clonal propagation, farmers' practices, genetic resources, in situ conservation, Manihot, manioc, sexual reproduction, technical ecological knowledge

Index géographique : Amazonie 


\section{AUTEURS}

DOYLE MCKEY

Université Montpellier II et Centre d'Écologie Fonctionnelle et Évolutive UMR 5175 CNRS, 1919 route de Mende, 34293 Montpellier cedex 5, France doyle.mckey@cefe.cnrs.fr

\section{MARIANNE ELIAS}

Muséum National d'Histoire Naturelle

Laboratoire Origine, Structure et Évolution de la Biodiversité

UMR 7205 CNRS, 45 rue Buffon, CP 50, 75005 Paris, France

et

Centro de Investigação em Biodiversidade e Recursos Genéticos (CIBIO-UP)

Campus Agrário de Vairão, 4485 - 661, Vairão, Portugal

melias2008@googlemail.com

\section{BENOÎT PUJOL}

Laboratoire Évolution et Diversité Biologique

UMR 5174, Bâtiment 4R3, Université Paul Sabatier, 31062 Toulouse cedex 9, France

pujol@cict.fr

\section{ANNE DUPUTIÉ}

Université Montpellier II et Centre d'Écologie Fonctionnelle et Évolutive UMR 5175 CNRS, 1919 route de Mende, 34293 Montpellier cedex 05, France et

Section of Integrative Biology

University of Texas at Austin, 1 University Station C0930 Austin, TX 78712 USA anne.duputie@ens-lyon.org

\section{MARC DELÊTRE}

Botany Department, School of Natural Sciences

Trinity College, University of Dublin, Dublin 2, Ireland

et

Muséum National d'Histoire Naturelle

Département Hommes, Natures, Sociétés

UMR 7206, Eco-Anthropologie et Ethnobiologie

CP 135, 57 rue Cuvier, 75231 Paris cedex 05, France

deletre@mnhn.fr

\section{DELPHINE RENARD}

Université Montpellier II et Centre d'Écologie Fonctionnelle et Évolutive UMR 5175 CNRS, 1919 route de Mende, 34293 Montpellier cedex 05, France delphine.renard@cefe.cnrs.fr 